\title{
Role of Aminolevulinic Acid in Stress Adaptation and Crop Productivity
}

\author{
Manisha Phour ${ }^{1 *}$, Anjali Ghai ${ }^{1}$, Gaurav Rose ${ }^{2}$, Nisha Dhull ${ }^{2}$ and Satyavir Singh Sindhu ${ }^{3}$ \\ ${ }^{1}$ Defence Institute of High Altitude Research (DIHAR), DRDO C/O 56 APO, India \\ ${ }^{2}$ Department of Microbiology, Panjab University, Chandigarh-160014, India \\ ${ }^{3}$ CCS Haryana Agricultural University, Hisar-125004, India \\ *Corresponding author
}

\section{Keywords}

Aminolevulinic acid,

Crop productive, Stress

adaptation, Bioherbicide

Article Info

Accepted:

12 April 2018

Available Online:

10 May 2018

\section{A B S T R A C T}

Aminolevulinic acid (ALA) is found as one of the potential plant growth regulator which is involved in the development of heme, chlorophyll, bilins, vitamin B and other specialized plant products. ALA has a significant role in stress adaptation in plants through regulating several key physiological processes associated with plant adaptations such as seed germination, reduced $\mathrm{Na}^{+}$uptake, altered light reactions, improved scavenging of reactive oxygen species, enhanced photosynthetic assimilation and maintenance of nutrients status. ALA also acts as a potential biodegradable herbicide and its herbicidal activity enhances accumulation of different chlorophyll intermediates, such as protochlorophyllide, protoporphyrin IX and Mg-protoporphyrin IX. Therefore, there are immense possibilities to increase crop productivity through application of ALA under different stress conditions.

\section{Introduction}

5-aminolevulinic acid (ALA) is a key precursor in the biosynthesis of all porphyrin compounds, including heme, phytochrome, chlorophyll and vitamin B12. Now, it is emerging as a new phytohormone which also serves as new plant growth regulating substance (PGR). In recent years, ALA has received wide attention due to its potential use as herbicide ( $\mathrm{Xu}$ et al., 2015), insecticide (Yang et al., 2011), plant stimulator under different stress conditions (Kosar et al., 2015), antimicrobial drug (Malik et al., 1990) and photosensitizer for photodynamic therapy (Wachowska et al., 2011). When used in low concentration (Sasikala and Ramana, 1995), it has been considered an effective mean of minimizing various abiotic stresses and their various adverse effects in a number of agricultural crops by regulating a variety of physiobiochemical processes such as photosynthesis, stimulating fixation of $\mathrm{CO}_{2}$ in light, chlorophyll biosynthesis, nutrient uptake, antioxidant metabolism, and protein synthesis, which are directly or indirectly involved in the mechanism of stress tolerance. Thus, ALA could be used as a biofertilizer as it has a promotive effect on the growth and yield of several crops and vegetables under various environmental factors, salinity, drought, and extreme temperatures. 


\section{Biosynthesis of ALA}

$\mathrm{C}_{4}$ and $\mathrm{C}_{5}$ pathway: the routes for ALA production

The formation of the key intermediate for ALA biosynthesis proceeds via two different pathways (Fig. 1) (Sasaki et al., 2002). One is the Shemin pathway $\left(\mathrm{C}_{4}\right.$ pathway) that is present in mammals, birds, yeast, protozoa and the purple non-sulfur photosynthetic bacteria. Another pathway is the glutamate pathway $\left(\mathrm{C}_{5}\right.$ pathway) that exists in higher plants, algae, archaea and many bacteria, such as Escherichia coli and Salmonella typhimurium (Kang et al., 2011b). A few microorganisms have both $\mathrm{C}_{4}$ and $\mathrm{C}_{5}$ pathways e.g., Euglena gracilis (Weinstein and Beale, 1985) and Rubrivivax benzoatilyticus PS-5 (Sattayasamitsathit and Prasertsan, 2013).

\section{Microbial production of ALA}

ALA was mainly synthesized through chemical methods (Sasaki et al., 2002). However, chemical synthetic methods involve complicated processes and relatively give low yields with high costs. Therefore, microbial synthesis appears to be a good alternative in the view of promising applications of ALA with its numerous advantages. One such example includes the fact that ALA production can be naturally carried out through the biosynthetic pathway of organisms (especially microorganisms) in their cell factories which shortens the ALA production process (Liu et al., 2014). The microbial synthesis of ALA in cells is tightly regulated by feedback inhibition at the level of ALA formation. In most microorganisms, synthesis of ALA for cell growth and metabolism requires limited carbon sources (Table 1). R. sphaeroides produced the highest ALA concentration $(4.2 \mathrm{mM})$ in media by anaerobic-light cultivation under optimized conditions. However, this concentration is still low for economic consideration. The lengthy fermentation time and light requirement during culture growth also make $R$. sphaeroides undesirable for industrial production.

\section{Applications}

ALA is reported to have the ability to promote plant growth, productivity and enhance stress tolerance, such as chilling (Korkmaz et al., 2010), drought (Liu et al., 2013), and salinity (Youssef and Awad, 2008; Naeem et al., 2012). The ALA also suppresses the respiration and the release of $\mathrm{CO}_{2}$ under dark (Hotta et al., 1997a, b). The appropriate applications of ALA showed 10-60\% promotive effect over the control on radish, kidney beans, barley, watermelon, potatoes, garlic, rice and corn (Sasikala et al., 1994). Therefore, 5-aminolevulinic acid (ALA), is known to be effective in counteracting the injurious effects of various abiotic stresses in plants.

\section{Salt adaptation}

Salinity is one of the major threats to agricultural crop production worldwide. Therefore, many approaches have been used to alleviate salinity stress of various crops; one of which is the use of 5- aminolevulinic acid plant growth regulators (PGRs). Research conducted on ALA has mainly focused on photosynthesis (Liu et al., 2013), chlorophyll accumulation (Memon et al., 2009), the antioxidant system (Sun et al., 2009), and ion uptake (Naeem et al., 2010). Although ALA has been reported to be capable of enhancing the salt tolerance of various plants, data on the molecular mechanism of ALA application are limited. Naeem et al., (2010) observed that spraying ALA on oilseed rape improved leaf water relations under salinity stress. They found that ALA could regulate the transcription of aquaporins in cucumber leaves 
and enhance the salt tolerance of the plants (Yan et al., 2014). Therefore, analyzing the effects of ALA on the expression of aquaporins in tomato seedlings and to determine the interaction between aquaporin expression and water content of tomato leaves under different salinity conditions. Yang et al., (2014) showed the exogenous application of ALA was effective for mitigating salinity damages in creeping bentgrass. The effects of ALA in creeping bentgrass were associated with the suppression of $\mathrm{Na}+$ toxicity and enhanced water retention, photosynthetic activities, antioxidant metabolism, and the accumulation of organic acids, amino acids, and sugars involved in osmotic regulation and respiratory pathways, and protein metabolism, as well as stress protection from membrane damages. Zhao et al., (2015) also studied that exogenous ALA application significantly improved net photosynthetic rate $(P \mathrm{n})$, total chlorophyll content, and plant biomass accumulation of tomato seedlings under salinity stress.

\section{Mechanism involved salt stress}

Salt stress is known to adversely affect endogenous levels of phytohormones that influence a variety of processes in plants such as reducing seed germination, seedling growth, ion uptake, stomata opening, and photosynthetic rate (Iqbal et al., 2010). In Sorghum, Netondo et al., (2004) observed that maximum quantum yield of photosystem II (Fv/Fm), photochemical quenching coefficient (qP) and electron transport rate (ETR) significantly decreased, but nonphotochemical quenching (NPQ) increased substantially under saline conditions. Sensitivity to salt stress in cereals might, thus, be associated with both reduction in PSII photochemical efficiency and enhanced NPQ to dissipate excess energy. Consequently, saline soil has detrimental effects on plant growth and yield. Ashraf and Harris (2004) reported reactive oxygen species (ROS) such as singlet oxygen $\left(1 \mathrm{O}_{2}\right)$, superoxide anion $\left(\mathrm{O}_{2}-\right)$, hydrogen peroxide $\left(\mathrm{H}_{2} \mathrm{O}_{2}\right)$ and hydroxyl radical $(\bullet \mathrm{OH})$, are produced in normal aerobic metabolism, but their levels are increased under stress. In plants, changes in antioxidative enzyme activities such as catalase (CAT), ascorbic peroxidase (APx), glutathione reductase (GR) and superoxide dismutase (SOD) involved in the detoxification of ROS, are often observed under salt stress.

ALA has been reported to increase ascorbateglutathione cycle activity and to increase the level of antioxidant enzymes such as SOD, CAT, and APx (Wongkantrakorn et al., 2009). It has been repeatedly demonstrated that the problems caused by salinity can be counteracted by use of ALA (Naeem et al., 2011). There have been a number of demonstrations that ALA at low concentrations can promote plant growth (Zhen et al., 2012; Ali et al., 2013) and their exogenous application of ALA is very effective in minimizing the salt-induced adverse effects in various crops, e.g. spinach (Spinaciaoleracea) (Nishihara et al., 2003), pakchoi (Brassica campestris) (Wang et al., 2005), potato (Solanum tuberosum) (Zhang et al., 2006), date palm (Phoenix dactylifera) (Youssef and Awad, 2008) and oilseed rape (Brassica napus) (Naeem et al., 2011). Unfortunately, commercial ALA is too expensive for many common agricultural applications. The use of microorganisms that directly produce ALA may be a lower cost.

\section{Cold adaptation}

Low temperature may impose stress on plant growth in a two-fold manner: by the effects of low temperature alone, and by dehydration of the cells and tissues when cellular water freezes (Beck et al., 2007). Low temperatures are deleterious to many crops of the tropics and subtropics which cannot acclimatize to 
cold. This kind of damage on the plant has been termed 'chilling' (Sakai and Larcher, 1987). These effects include damaged membranes (Xing and Rajashekar, 2001), reduced cellular respiration (Lee et al., 1997), increased abscisic acid levels (Nayyar et al., 2005), cryoprotectants and increased reactive oxygen species (Lee et al., 1997) which arises from imbalances of electron transport rate and the metabolic consumer activity of the reductive power (Beck et al., 2007). Most temperate plants can cold-acclimate. They acquire tolerance to extracellular ice formation in their vegetative tissues, while many important crops, such as rice, maize, soybean and cotton are chilling sensitive and incapable of cold acclimation. Recently, it was found that ALA has a promotive effect on growth and yield of several field crops (Watanabe et al., 2000). Zhang et al., (2006) observed that ALA increased cold and salt tolerance in rice and potato. It has been reported that ALA biosynthesis in plants is inhibited by low and high temperatures (Hodgins and Oquist, 1989; Tewari and Tripathy, 1998). From previous studies, exogenous application of ALA could enhance the antioxidant level in spinach and pakchoi (Memon et al., 2009) and enhance plant's tolerance to cold stress (Wang et al., 2004).

ALA pre-treatment also increased reduced glutathione (GSH), ascorbic acid (AsA), total glutathione, and total ascorbate concentrations, and the activities of superoxide dismutase (SOD), catalase (CAT), ascorbate peroxidase (APX) and glutathione reductase (GR), whereas decreased the contents of malondialdehyde (MDA) and hydrogen peroxide $\left(\mathrm{H}_{2} \mathrm{O}_{2}\right)$, and superoxide radical $\left(\mathrm{O}_{2} \mathrm{~N}_{2}\right)$ release in germinating seeds under cold stress. The results indicate that ALA considered as an endogenous plant growth regulator could effectively protect $E$. nutans seeds from cold-induced oxidative damage during germination without any adverse effect. Manafi et al., (2015) evaluated the effect of exogenous ALA enhancing cold stress tolerance of young soybean plants (Glycine max). Therefore, exogenous application of ALA is a novel strategy and has been considered as an effective means of minimizing the cold induced adverse effects.

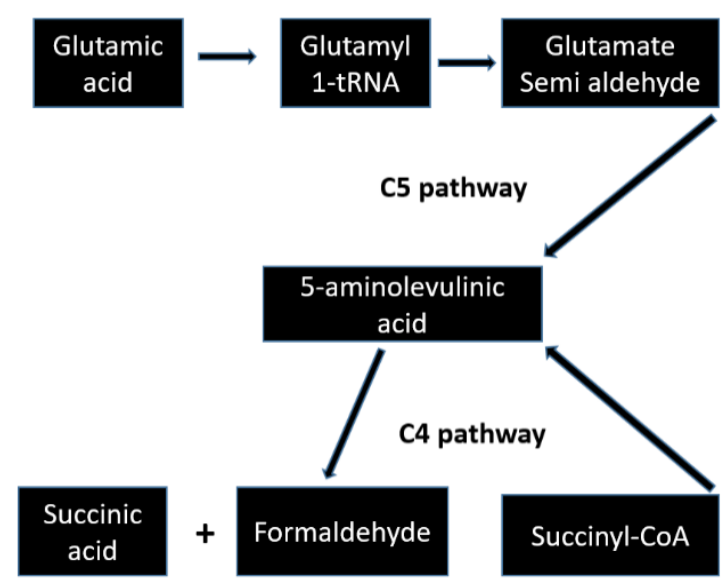

Fig. $1 \mathrm{C}_{5}$ and $\mathrm{C}_{4}$ pathways for ALA biosynthesis 

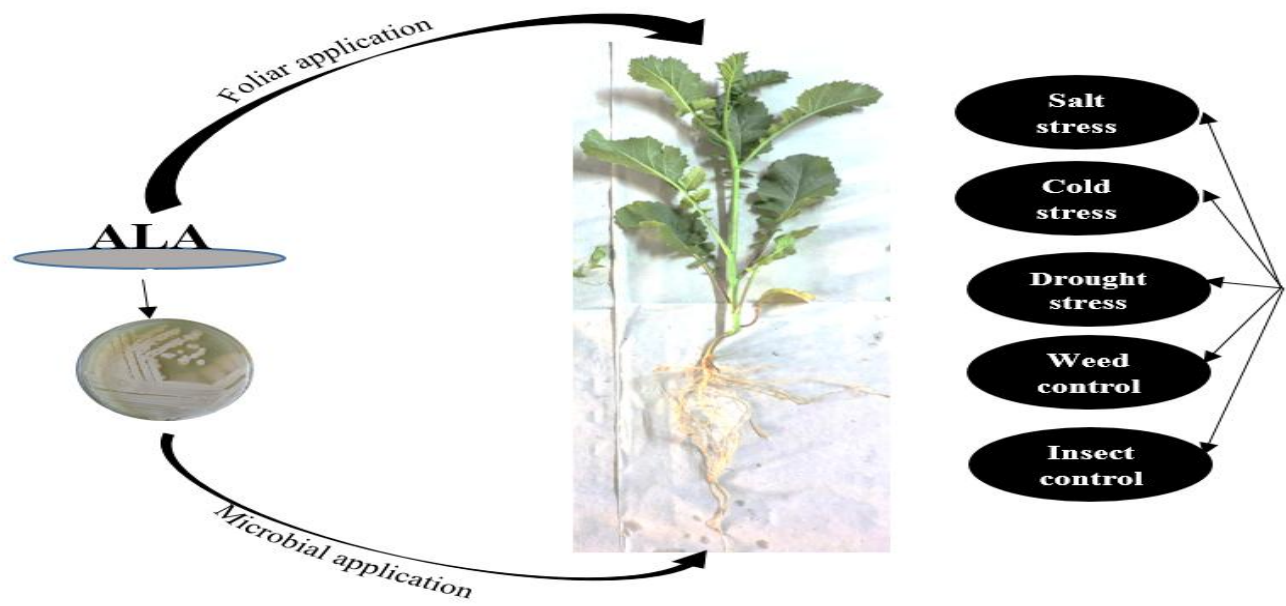

Applications

Table.1 Production of $\delta$-aminolevulinic acid by bacteria

\begin{tabular}{|c|c|c|c|}
\hline Microorganisms & Carbon source & $\operatorname{ALA}(\mu \mathrm{M})$ & References \\
\hline $\begin{array}{l}\text { Rhodopseudomonas } \\
\text { palustris }\end{array}$ & Glycine and succinate & 2.61 & Kantha et al., 2015 \\
\hline Rhodovulum sp. & Glutamate, glycine & 2.0 & Noparatnaraporn et al., 2000 \\
\hline Rubrivivax benzoatilyticus & $\begin{array}{l}\text { Glycine, succinate and } \\
\text { levulinic acid }\end{array}$ & 190.74 & $\begin{array}{l}\text { Sattayasamitsathit and } \\
\text { Prasertsan, } 2013\end{array}$ \\
\hline Rhodopseudomonas sp.KL9 & $\begin{array}{l}\text { Malate, succinate and } \\
\text { acetate }\end{array}$ & 67.2 & Hyun and Song, 2007 \\
\hline Rhodobacter capsulatus & Glutamate effluent & 40 & Chaikritsadakarn et al., 2004 \\
\hline $\begin{array}{l}\text { Rhodopseudomonas } \\
\text { palustris KG31 }\end{array}$ & Glutamate, acetate & 0.18 & Saikeur et al., 2009 \\
\hline R. sphaeroides & $\begin{array}{l}\text { Glucose, glycine, } \\
\text { levulinic acid }\end{array}$ & 20.0 & Nishikawa et al., 1999 \\
\hline R. sphaeroides CR720 & Glucose, glycine & 27.5 & Kamiyama et al., 2000 \\
\hline
\end{tabular}

\section{Drought adaptation}

Water is the key requirement for plant growth and productivity. Drought stress results in the generation and accumulation of active oxygen species, peroxidation of membrane lipids and impairment of nitrogen metabolism, photosynthesis, growth, and development, causing a substantial decline in yield and quality (Li et al., 2014). Li et al., (2011) reported promoting effect of ALA in a cucumber variety (Cucumis sativus L. cv.
Yuexiu no. 3). Seeds were pretreated with $3 \mu \mathrm{M}$ ALA for 2 days and then were exposed to drought stress induced by $10 \%$ polyethylene glycol (PEG) 6000. After 2 days of ALA pretreatment, no changes were observed in plant growth indexes including plant heights and the fresh and dry weights of shoots and roots and the second leaves. Drought stress increased the activities of superoxide dismutase (SOD, EC 1.15.1.1), guaiacol peroxidase (GPX, EC 1.11.1.7), glutathione peroxidase (GSH-Px, EC 
1.11.1.9), ascorbate peroxidase (APX, EC 1.11.1.11), glutathione reductase (GR, EC 1.6.4.2), and monodehydroascorbatereductase (MDHAR, EC 1.6.5.4) in ALA-pretreated leaves. The results indicated ALA pretreatment protects cucumbers from drought stress.

Liu et al., (2011) evaluated the effects of 5aminolevulinic acid (ALA, 0, 0.1, 1 and $10 \mathrm{mg}^{-1}$ ) on the growth of oilseed rape (Brassica napus L. cv. ZS758) seedlings under water-deficit stress induced by polyethylene glycol (PEG 6000, 0 and $-0.3 \mathrm{MPa}$ ). Water-deficit stress imposed adverse effects on seedling growth by reducing shoot biomass, cotyledon water potential, chlorophyll content and nonenzymatic antioxidants (glutathione and ascorbic acid) levels.

Application of ALA at lower dosages ( 0.1 and $1 \mathrm{mg} \mathrm{l}^{-1}$ ) improved shoot growth and chlorophyll contents and whereas moderately higher dosage of ALA (10 $\mathrm{mg} \mathrm{l}^{-1}$ ) hampered the growth. The study also indicated that $1 \mathrm{mg} \mathrm{l}^{-1}$ ALA improved chlorophyll content, but reduced malondialdehyde (MDA) content and ROS production significantly under water-deficit stress. Lower dosages of ALA (0.1 and $1 \mathrm{mg} \mathrm{l}^{-1}$ ) also enhanced reduced/oxidized glutathione ratio (GSH/GSSG) and reduced/oxidized ascorbic acid (ASA/DHA) as compared to the seedlings under water-deficit stress. The antioxidant enzymes (ascorbate peroxidase, peroxidase, catalase, glutathionereductase and superoxide dismutase) enhanced their activities remarkably with $1 \mathrm{mg} \mathrm{l}^{-1}$ ALA treatment under water-deficit stress. These results indicated that $0.1-1 \mathrm{mg}^{-1}$ ALA could enhance the water-deficit stress tolerance of oilseed seedlings through improving the biomass accumulation, maintaining a relative high ratio of GSH/GSSG and ASA/DHA, enhancing the activities of the specific antioxidant enzymes and inducing the expression of the specific antioxidant enzyme genes.

\section{Bioherbicide}

ALA has received great attention as a biodegradable herbicide (Chon, 2003). However, herbicidal activity of ALA on several plants was affected by the application methods. At low concentration (0.01-10 $\mathrm{mg} / \mathrm{L})$, ALA showed growth promoting effects on yield of several crops (Hotta et al., 1997b), whereas it suppressed plant growth at higher concentrations $(>2 \mathrm{mM})$. Its application is harmless to crops, humans and animals (Edwards et al., 1984; Beck et al., 2007; Bhowmick and Girotti, 2010; Mikolajewska et al., 2010; Kang et al., 2012). Zhang et al., (2006) reported that ALA at low concentrations of $0.3-3 \mathrm{mg} / \mathrm{L}$ promoted development and growth of potato microtubers in vitro and enhanced protective functions against oxidative stresses, but ALA at $30 \mathrm{mg} / \mathrm{L}$ and higher concentrations may induced oxidative damage.

ALA has photodynamic herbicide properties under appropriate treatment conditions. An immediate dark-incubation period after spraying ALA is an essential step to accumulate tetrapyrrole within the plants. ALA serves as a building block of tetrapyrrole accumulation, while a group of modulators, $O$-phenanthroline, ethyl nicotinate and 2, 2'-depyridyl (DP), were found to affect the pattern of tetrapyrrole accumulation and acted in concert with ALA. DP is a cheap chemical and it is selected to mix with ALA to enhance the accumulation of tetrapyrrole. During the daylight period, the excess tetrapyrrole produces active oxygen (singlet oxygen), which oxidizes the unsaturated fatty acid on the cell surface (lipoprotein component), thus setting in motion a greatly damaging free-radical chain reaction. The cell membranes become leaky 
and this, in turn, resulted in a rapid and severe dehydration, bleaching and collapse of the leaf and/or hypocotyl tissue (Rebriz et al., 1984). Within $24 \mathrm{~h}$, the green plant tissue turns into a brownish desiccated mass of dead tissue (Rebriz et al., 1990). On the other hand, treated plants kept for the same period of time in darkness were unaffected. The accumulation of tetrapyrrole in plant leaves causes very severe photodynamic damage and the leaves die within a few hours while the cotyledons, stem and growing point remain unaffected. Dicotyledonous weeds such as redroot pigweed, purslane and lambquarter are highly susceptible to the tetrapyrrole induced photodynamic damage. Monocots such as corn, wheat, oats and barley were not adversely affected by the spray (Rebriz et al., 1984). The death of plants depended on the age of plant, ALA concentration, type of modulators, ratio of ALA and modulator, light intensity and varieties of plant treated (Kobayashi and Haque, 1971).

\section{Perspective and Future aspects}

Due to serious problems such as environmental pollution, energy crisis, global warming and an increasing demand of sustainable development, bio-based production of industrial chemicals, pharmaceuticals and biofuels, have been received much attention and intense research. In the past decades, many good characterized native strains for ALA production were screened and isolated. Further research at molecular levels may be necessary to identify molecular and metabolic pathways conferring ALA effects on stress mitigation/herbicidal effect in different plant species.

\section{References}

Ali, B., Tao, Q., Zhou, Y., Gill, R.A., Ali, S. and Rafiq, M.T. (2013) 5-Aminolevolinic acid mitigates the cadmium-induced changes in Brassica napus as revealed by the biochemical and ultra-structural evaluation of roots. Ecotoxicology Environment Safety 92: 271-280.

Beck, E. H., Heim, R., and Hansen, J. (2004). Plant resistance to cold stress: mechanisms and environmental signals triggering frost hardening and dehardening. Journal of Biosciences, 29(4), 449-459.

Beck, T.J., Kreth, F.W., Beyer, W., Mehrkens, J.H., Obermeier, A., Stepp, H., Stummer, W. and Baumgartner, R. (2007) Interstitial photodynamic therapy of nonresectable malignant glioma recurrences using 5aminolevulinic acid induced protoporphyrin IX. Lasers Surgery and Medicine 39: 386393.

Hodgins, R. R. W., and Öquist, G. (1989). Porphyrin metabolism in chill- stressed seedlings of Scots pine (Pinus sylvestris). Physiologia Plantarum, 77(4), 620-624.

Hotta, Y., Tanaka, H., Takaoka, Y., Takeuchi, Y. and Konnai, M. (1997a) Promotive effects of 5-aminolevulinic acid on the yield of several crops. Plant Growth Regulation 22: 109-114.

Hotta, Y., Watanabe, K., Tanaka, T., Takeuchi, Y. and Konnai, M. (1997b) Effects of 5aminolevulinic acid on growth of plant seedlings. Journal of Pesticide Science 22:102-107.

Iqbal, U., Jamil, N., Ali, I. and Hasnain, S. (2010) Effect of zinc and phosphate-solubilizing bacterial strains on growth of Vigna radiata. Annals of Microbiology 61: 1869-2044.

Kantha, T., Kantachote, D. and Klongdee, N. (2015) Potential of biofertilizers from selected Rhodopseudomonas palustris strains to assist rice (Oryza sativa L. subsp. indica) growth under salt stress and to reduce greenhouse gas emissions. Annals of Microbiology 65(4): 2109-2118.

Korkmaz, A., Korkmaz, Y. and Demirkıran, A.R. (2010) Enhancing chilling stress tolerance of pepper seedlings by exogenous application of 5-aminolevulinic Acid. Environmental and Experimental Botany 67: 495-501.

Kosar, F., Akram, N.A and Ashraf, M. (2015) Exogenously applied 5-aminolevulinic acid modulates some key physiological characteristics and antioxidative defense system in spring wheat (Triticum aestivum 
L.) seedlings under water stress. South African Journal of Botany 96: 71-77.

Lee, T. M., Lur, H. S., \& Chu, C. (1997). Role of abscisic acid in chilling tolerance of rice (Oryza sativa L.) seedlings: II. Modulation of free polyamine levels. Plant Science, 126(1), 1-10.

Li, C., Tan, D. X., Liang, D., Chang, C., Jia, D., \& Ma, F. (2014). Melatonin mediates the regulation of $\mathrm{ABA}$ metabolism, free-radical scavenging, and stomatal behaviour in two Malus species under drought stress. Journal of Experimental Botany, 66(3), 669-680.

Liu D, Wu LT, Naeem MS, Liu HB, Deng XQ, et al., (2013) 5-Aminolevulinic acid enhances photosynthetic gas exchange, chlorophyll fluorescence and antioxidant system in oilseed rape under drought stress. Acta Physiology Plant 35: 2747-2759.

Malik, Z., Hanania, J. and Nitzan, Y. (1990) New trends in photobiology: bactericidal effect of photoactivated porphyrins-an alternative approach to antimicrobial drugs. Journal of Photochemistry and Photobiology B Biology 5: 281-293.

Manafi, E., ModarresSanavy, S.A.M., Aghaalikhani, M. and Dolatabadian, A. (2015) Exogenous 5-aminolevulenic acid promotes antioxidative defence system, photosynthesis and growth in soybean against cold stress. Notulae Scientia Biologicae 7(4): 486-494.

Memon, S. A., Hou, X., Wang, L., \& Li, Y. (2009). Promotive effect of 5-aminolevulinic acid on chlorophyll, antioxidative enzymes and photosynthesis of Pakchoi (Brassica campestris ssp. chinensis var. communis Tsenet Lee). Acta Physiologiae Plantarum 31(1), 51-57.

Naeem MS, Warusawitharana H, Liu H, Liu D, Ahmad R, et al., (2012) 5Aminolevulinic acid alleviates the salinity-induced changes in Brassica napus as revealed by the ultrastructural study of chloroplast. Plant Physiology and Biochemistry 57: 84-92.

Naeem, M.S., Jin, Z.L., Wan, G.L., Liu, D., Liu, H.B., Yoneyama, K. and Zhou, W.J. (2010) 5-Aminolevulinic acid improves photosynthetic gas exchange capacity and ion uptake under salinity stress in oilseed rape
(Brassica napus L.). Plant Soil 332: 405415.

Naeem, M.S., Rasheed, M., Liu, D. and Jin, Z.L. (2011) 5-Aminolevulinic acid ameliorates salinity-induced metabolic, water-related and biochemical changes in Brassica napus L. Acta Physiologiae Plantarum 33: 517-528.

Nayyar, H., Bains, T. S., \& Kumar, S. (2005). Chilling stressed chickpea seedlings: effect of cold acclimation, calcium and abscisic acid on cryoprotective solutes and oxidative damage. Environmental and Experimental Botany, 54(3), 275-285.

Netondo, G.W., Onyango, J.C. and Beck, E. (2004) Sorghum and salinity: II. Gas exchange and chlorophyll fluorescence of sorghum under salt stress. Crop Science 44: 806-811.

Nishihara, E., Kondo, K., Parvez, M.M., Takahashi, K., Watanabe, K. and Tanaka, K. (2003) Role of 5- aminolevulinic acid (ALA) on active oxygen-scavenging system in $\mathrm{NaCl}$ treated spinach (Spinacia oleracea). Plant Physiology 160: 1085-1091.

Sakai, A., \& Larcher, W. (1987). Frost Survival of Plants. Eco-logical Studies 62.

Sasikala, Ch., Ramana, Ch.V. and Rao, P.R. (1994) 5-aminolevulinic acid: A potential herbicide/insecticide from microorganisms. Biotechnology Progress 10: 451-459.

Sun, Y.P., Zhang, Z.P. and Wang, L.J. (2009) Promotion of 5-aminolevulinic acid treatment on leaf photosynthesis is related with increase of antioxidant enzyme activity in watermelon seedlings grown under shade condition. Photosynthetica 47(3): 347-354.

Tewari, A. K., and Tripathy, B. C. (1998). Temperature-stress-induced impairment of chlorophyll biosynthetic reactions in cucumber and wheat. Plant physiology, 117(3), 851-858.

Wachowska, M., Muchowicz, A., Firczuk, M., Gabrysiak, M., Winiarska, M., Wanczyk, M., Bojarczuk, K. and Golab, J. (2011) Aminolevulinic acid (ALA) as a prodrug in photodynamic therapy of cancer. Molecules 16: 4140-4164

Wang, J.J., Jiang, W.B., Liu, H., Liu, W.Q., Kang, L. and Hou, X.L. (2005) Promotion by 5aminolevulinic acid of germination of pakchoi (Brassica campestris ssp. Chinensis 
var. communisTsenet Lee) seeds under salt stress. Journal of Integrative Plant Biology 47: 1084-1091.

Watanabe, K., Tanaka, T., Hotta, Y., Kuramochi, H. and Takeuchi, Y. (2000) Improving salt tolerance of cotton seedlings with 5aminolevulinic acid. Plant Growth Regulation 32: 99-103.

Wongkantrakorn, N., Sunohara, Y. and Matsumoto, H. (2009) Mechanism of growth amelioration of $\mathrm{NaCl}$-stressed rice (Oryza sativa L.) by $\delta$-aminolevulinic acid. Journal of Pesticide Science 34: 89-95.

Xing, W., \& Rajashekar, C. B. (2001). Glycine betaine involvement in freezing tolerance and water stress in Arabidopsis thaliana. Environmental and Experimental Botany, 46(1), 21-28.

$\mathrm{Xu}$, L., Zhang, W., Ali, B., Islam, F., Zhu, J. and Zhou, W. (2015) Synergism of herbicide toxicity by 5 -aminolevulinic acid is related to physiological and ultra-structural disorders in crickweed (Malachium aquaticum L.). Pesticide Biochemistry and Physiology125: 53-61.

Yan, F., Qu, D., Zhao, Y.Y. and Hu, X.H. (2014) Effects of exogenous 5-aminolevulinic acid on PIP1 and NIP aquaporin gene expression in seedlings of cucumber cultivars subjected to salinity stress. Genetics and Molecular Research 13: 2563-2573.

Yang, M., Yin, K., Guo, Y., Ma, E. and Zhang, J. (2011) A photosensitivity insecticide, 5 aminolevulinic acid, exerts effective toxicity to Oxyachinensis (Orthoptera: Acridoidea). Agricultural Science in China 10(7): 10561063.

Yang, Z., Chang, Z., Sun, L., Yu, J. and Huang, B. (2014) Physiological and metabolic effects of 5-aminolevulinic acid for mitigating salinity stress in creeping bentgrass. PLoS ONE 9(12): e116283.

Youssef, T. and Awad, M.A. (2008) Mechanisms of enhancing photosynthetic gas exchange in date palm seedlings (Phoenix dactylifera L.) under salinity stress by a 5-aminolevulinic acid-based fertilizer. Journal of Plant Growth Regulation 27: 1-9.

Zhang, Z.J., Li, H.Z., Zhou, W.J., Takeuchi, Y. and Yoneyama, K. (2006) Effect of 5aminolevulinic acid on development and salt tolerance of potato (Solanum tuberosum L.) microtubers in vitro. Plant Growth Regulation 49: 27-34.

Zhao, Y.Y., Yan, F., Hu, L.P., Zhou, X.T., Zou, Z.R and Cui, L.R. (2015) Effects of exogenous 5-aminolevulinic acid on photosynthesis, stomatal conductance, transpiration rate and PIP gene expression of tomato seedlings subject to salinity stress. Genetics and Molecular Research 14 (2): 6401-6412.

Zhen, A., Bie, Z.L., Huang, Y., Liu, Z.X. and Fan, M.L. (2012) Effects of 5-aminolevulinic acid on the $\mathrm{H}_{2} \mathrm{O}_{2}$ content and antioxidative enzyme gene expression in $\mathrm{NaCl}$ treated cucumber seedlings. Biologia Plantarum 56: $566-570$.

\section{How to cite this article:}

Manisha Phour, Anjali Ghai, Gaurav Rose, Nisha Dhull and Satyavir Singh Sindhu. 2018. Role of Aminolevulinic Acid in Stress Adaptation and Crop Productivity. Int.J.Curr.Microbiol.App.Sci. 7(05): 1516-1524. doi: https://doi.org/10.20546/ijcmas.2018.705.178 